\title{
Substituição do milho pela raspa de mandioca em dietas para vacas primíparas em lactação ${ }^{1}$
}

\author{
Ricardo Pimentel Ramalho2 ${ }^{2}$, Marcelo de Andrade Ferreira ${ }^{3,5}$, Antonia Sherlânea Chaves \\ Véras $^{3}$, Luiz Evandro de Lima ${ }^{4}$, Vitória Régia Ramos de Albuquerque Rocha ${ }^{6}$ \\ ${ }^{1}$ Parte da tese de Doutorado do primeiro autor - PDIZ - UFPB/ UFRPE/ UFC. Trabalho realizado por intermédio do acordo IPA/UFRPE. \\ 2 CCBS/FEJAL - CESMAC. \\ ${ }^{3}$ Departamento de Zootecnia/UFRPE. \\ 4 IPA. \\ ${ }^{5}$ Bolsista de Produtividade em Pesquisa do CNPq. \\ ${ }^{6}$ Mestre em Zootecnia - PPGZ - UFRPE.
}

RESUMO - Com o objetivo de avaliar a influência de níveis de substituição do milho moído pela raspa de mandioca no desempenho dos animais, no consumo e na digestibilidade dos nutrientes de dietas à base de palma forrageira (Opuntia ficus indica, Mill) e silagem de sorgo, cinco vacas primíparas da raça Holandesa (60 15 dias em lactação e $448 \mathrm{~kg}$ de PV inicial) foram distribuídas em um único quadrado latino (5 x 5). A raspa de mandioca substituiu 0, 25, 50,75 e $100 \%$ do milho moído nas dietas. Os consumos e a digestibilidade de MS (em kg/dia, \% do PV, g/kg0,75 do PV), MO, PB, EE, CNF, CHOT, FDA, FDN e NDT não foram influenciados pelos níveis de raspa de mandioca nas dietas. A produção de leite, a produção de leite corrigida para 3,5\% de gordura e a produção de gordura decresceram linearmente em 20,30 e 1,15 g/dia, respectivamente. A eficiência alimentar ( $\mathrm{kg}$ de leite corrigido para 3,5\% de gordura/kg de MS) diminuiu linearmente em 0,001 para cada unidade de inclusão da raspa de mandioca, enquanto o teor de gordura não foi influenciado pelos níveis de substituição do milho moído nas dietas

Palavras-chave: consumo, digestibilidade, eficiência alimentar, produção de leite, produção de gordura

\section{Replacement of corn with cassava scrapings in diets for primiparous lactating Holstein cows}

\begin{abstract}
This study was conducted to evaluate replacement of ground corn grain with cassava scrapings on nutrient intake, digestibility, and production of primiparous Holstein lactating dairy cows receivind diets containing forage cactus (Opuntia ficus indica, Mill), sorghum silage and concentrate. Five cows averaging $60 \pm 15$ of days in milk and initial body weight (BW) of $448 \mathrm{~kg}$ were randomly assigned to a $5 \times 5$ Latin square with increasing levels of cassava scrapings in the diet: 0,25 , 50,75 or $100 \%$. Intakes of dry matter $(\mathrm{DM})\left(\mathrm{kg}, \% \mathrm{BW}\right.$ and $\left.\mathrm{g} / \mathrm{BW} \mathrm{kg}{ }^{0.75}\right)$, organic matter $(\mathrm{OM})$, crude protein $(\mathrm{CP})$, ether extract (EE), nonfiber carbohidrates (NFC), total carbohydrates (TCHO), acid detergent fiber (ADF), neutral detergent fiber (NDF), and total digestible nutrients (TDN) all were not affected by replacing ground corn with cassava scrapings in the diet Similarly, increasing the dietary levels of cassava scrapings did not affect apparent digestibilities of nutrients $(P>0.05)$ However, milk yield, milk yield corrected for 3.5\% fat, and fat yield decreased linearly by 20,30 and, 1.15 g/day, respectively, when corn grain was replaced with cassava scrapings. Feed efficiency, expressed as $\mathrm{kg}$ of $3.5 \%$ fat corrected milk per $\mathrm{kg}$ of $\mathrm{DM}$, also decreased linearly by 0.001 per each unit of cassava scrapings added to the diet. No significant differences for milk fat content were observed among treatments in this trial.
\end{abstract}

Key Words: digestibility, fat yield, intake, feed efficiency, milk yield

\section{Introdução}

Os grãos de cereais caracterizam-se por sua importância na composição energética de rações para a alimentação animal. Esses grãos, ricos em carboidratos, constituem a principal fonte de energia para bovinos e normalmente compõem 60 a 70\% do total da dieta desses animais (Silva \& Leão, 1979; Zeoula \& Caldas Neto, 2001).
Nocek \& Taminga (1991) afirmaram que a principal função dos carboidratos consiste no provimento de energia para a microbiota ruminal e para o animal hospedeiro. Outra função - secundária, mas essencial - é a manutenção fisiológica do trato gastrintestinal por certos tipos de carboidratos (NRC, 2001).

A crescente demanda para alimentação humana, em conjunto com as altas e freqüentes flutuações de seus 
preços no mercado, tornaram a inclusão desses grãos nas rações para vacas leiteiras uma opção menos econômica (Ribeiro et al., 1976). Nos concentrados utilizados pelos produtores de leite, o milho (principal grão de cereal) e o farelo de soja têm sido as principais fontes de energia e proteína, respectivamente. Porém, a utilização desses ingredientes aumenta consideravelmente o custo de produção do leite, se considerados a necessidade de suplementação aos animais no período de estiagem, o elevado custo de aquisição e a relativa escassez desses insumos na Região Nordeste.

Nesse contexto, a mandioca (Manihot esculenta, Crantz) e os variados subprodutos de sua industrialização destacam-se como substitutos energéticos mais baratos para formulação de rações para ruminantes, uma alternativa viável, pois possui valor nutritivo semelhante ao do milho e sua produção no Brasil é expressiva (Pereira, 1987).

Existe grande variação na composição bromatológica da mandioca e de seus subprodutos. Entretanto, esses alimentos possuem como característica comum altos teores de carboidratos não-estruturais, com predominância do amido, e baixo percentual de PB. O amido é o principal componente energético dos grãos e das raízes utilizados na alimentação de ruminantes e, em virtude de suas características como fonte de reserva, apresenta disponibilidade energética superior à dos carboidratos estruturais presentes nas dietas de ruminantes.

A utilização de fontes de amido é fundamental na exploração de animais de alta produção, os quais exigem níveis elevados de energia na dieta para que possam expressar todo o seu potencial genético. Além disso, segundo Zeoula \& Caldas Neto (2001), fontes de amido podem ser utilizadas para melhorar as características de fermentação ruminal, principalmente durante a utilização de fontes de nitrogênio não-protéico, possibilitando melhor utilização dos carboidratos estruturais e maior fluxo de proteína microbiana para o intestino delgado. Esses autores afirmam que a raiz de mandioca possui degradabilidade efetiva do amido superior à do milho, em razão da inexistência de pericarpo, endosperma córneo e periférico e matriz protéica e, possivelmente, por sua menor proporção de amilose e lipídios nos grânulos de amido, diminuindo a quantidade de pontes de hidrogênio na molécula e aumentando a capacidade de expansão do amido em meio aquoso.

A avaliação de ingredientes regionais que possam substituir total ou parcialmente alimentos convencionais e/ou combinar a outros de diferentes características digestivas justifica-se pela necessidade de formulação de dietas viáveis economicamente.
Diversos pesquisadores testaram, com sucesso, a substituição do milho pela mandioca (Ribeiro et al., 1976; Mello et al., 1976; Campero et al., 1994). Todavia, avaliaram dietas com pequena participação de concentrado em relação ao total de MS ingerida diariamente pelos animais.

Neste estudo, objetivou-se avaliar o desempenho, o consumo e a digestibilidade dos nutrientes em vacas Holandesas, primíparas lactantes, alimentadas com dietas à base de palma forrageira (Opuntia ficus indica, Mill) e silagem de sorgo contendo diferentes níveis de substituição do milho moído pela raspa de mandioca.

\section{Material e Métodos}

O experimento teve duração de 85 dias e foi realizado na Estação Experimental de São Bento do Una, pertencente à Empresa Pernambucana de Pesquisa Agropecuária - IPA, localizada no Agreste de Pernambuco.

Foram utilizadas cinco vacas primíparas da raça Holandesa aos $60 \pm 15$ dias em lactação, com peso vivo médio inicial de 448,4 kg e produção média inicial de $24,8 \mathrm{~kg}$ de leite por dia.

Os animais foram alojados em estábulo semicoberto, com cocho individual para controle do consumo. O arraçoamento foi realizado três vezes ao dia, às 6, 13 e $18 \mathrm{~h}$, nas proporções de 40,30 e $30 \%$, respectivamente, do total de MS oferecida. A palma forrageira (in natura) foi picada mecanicamente antes de ser misturada (no cocho) à silagem de sorgo e aos concentrados, sendo oferecida aos animais na forma de mistura completa. As sobras do dia anterior foram pesadas diariamente para manutenção de 5 a $10 \%$ do total de MS oferecido, visando diminuir a seletividade dos animais às dietas e não limitar o consumo por falta de alimento.

Foram realizadas três ordenhas diárias (às 5,12 e 20h), efetuando-se o registro da produção por animal e a coleta de amostras de leite em dois dias ( $11 \underline{\underline{o}}$ e $17 \underline{0}$ ) de cada período experimental, para determinação do teor de gordura, utilizando-se o método de Gerber, descrito por Behmer (1965). A produção de leite foi corrigida para 3,5\% de gordura (PLC), segundo Sklan et al. (1992).

Os tratamentos consistiram da inclusão de níveis crescentes de raspa de mandioca $(0 ; 5,64 ; 11,28 ; 16,92$ e $22,56 \%)$ nas dietas, em substituição a $0 ; 25 ; 50 ; 75$ e $100 \%$ do milho (Tabela 1). A raspa de mandioca foi obtida a partir da raiz desintegrada (casca e polpa), seca ao sol e moída, antes de ser incorporada às rações. Para composição de dietas isoprotéicas, foi necessário elevar o nível de inclusão de uréia nas dietas, uma vez que a mandioca possui menores teores de PB, com base na MS, se comparada ao milho. 
Foi utilizado o delineamento em quadrado latino $(5 \times 5)$, composto de cinco animais, cinco dietas e cinco períodos. Cada período teve duração de 17 dias, sendo dez para adaptação dos animais às dietas e sete para a coleta de dados e amostras.

As dietas foram formuladas conforme recomendações do NRC (2001) para atender às exigências de vacas com peso vivo de $500 \mathrm{~kg}$ produzindo $25 \mathrm{~kg}$ de leite/dia, com $3,5 \%$ de gordura.

Durante os sete dias do período experimental, as sobras referentes a cada animal foram pesadas e amostradas diariamente antes do fornecimento do alimento, quando também eram retiradas amostras das dietas. As amostras de alimentos e sobras foram pré-secas em estufa de ventilação forçada, a $60^{\circ} \mathrm{C}$, e acondicionadas em sacos de papel, para formarem, ao final de cada período experimental, de uma amostra composta por animal, por tratamento.

Ao final de cada período experimental, as amostras referentes a cada tratamento, por período, foram novamente armazenadas para análise posterior.

Amostras de fezes foram coletadas diretamente na ampola retal no $11^{\circ}$ e $17^{\circ}$ dias de cada período experimental e receberam o mesmo tratamento dado às sobras.
Amostras do alimento, das sobras e das fezes foram analisadas quanto aos teores de MS, de acordo com a AOAC (1980); CIN, EE e PB, conforme metodologia descrita por Silva (1990); e FDN e FDA, segundo Van Soest et al. (1991). A MO foi obtida pela diferença entre o teor de CIN e o total de MS. Os teores de CNF dos concentrados foram calculados, também por diferença, segundo Hall (1997), e os de CHOT, pelo somatório das frações de FDN e CNF.

O consumo dos nutrientes foi determinado pela diferença entre o total do nutriente nos alimentos ofertados e o total contido nas sobras.

As digestibilidades de MS foram estimadas utilizandose a FDAi (fibra em detergente ácido indigestível) como indicador interno, segundo Cochran et al. (1986), com adaptação da metodologia de incubação in vitro. Amostras de alimento, sobras e fezes de cada um dos níveis de substituição e períodos, foram incubadas por 144 horas no rúmen fistulado de um bovino macho adulto. Os coeficientes de digestibilidade aparente da MS e dos demais nutrientes foram estimados segundo Coelho da Silva \& Leão (1979).

Com base nas equações propostas pelo NRC (2001), foram calculados os nutrientes digestíveis totais de mantença $\left(\mathrm{NDT}_{1 \mathrm{x}}\right)$ e as energias líquidas de produção

Tabela 1 - Composição percentual da silagem de sorgo, da palma forrageira e das dietas experimentais, com base na matéria seca Table 1 - Chemical and ingredient composition of the experimental diets and chemical composition of sorghum silage (SS) and cactus forage (CF), on dry matter basis

\begin{tabular}{|c|c|c|c|c|c|c|c|}
\hline \multirow{2}{*}{\multicolumn{2}{|c|}{$\begin{array}{l}\text { Ingrediente } \\
\text { Ingredient composition, \% }\end{array}$}} & \multicolumn{6}{|c|}{$\begin{array}{c}\text { Nível de substituição (\%) } \\
\text { Replacement levels (\%) }\end{array}$} \\
\hline & & 0 & 25 & 50 & \multicolumn{2}{|c|}{75} & 100 \\
\hline \multicolumn{2}{|c|}{ Palma forrageira (Forage cactus) } & 29,00 & 29,00 & 29,00 & \multicolumn{2}{|c|}{29,00} & 29,00 \\
\hline \multicolumn{2}{|c|}{ Silagem de sorgo (Sorghum silage) } & 26,10 & 26,10 & 26,10 & \multicolumn{2}{|c|}{26,10} & 26,10 \\
\hline \multicolumn{2}{|c|}{ Milho moído (Ground corn grain) } & 23,06 & 17,30 & 11,53 & \multicolumn{2}{|c|}{5,76} & 0,00 \\
\hline \multicolumn{2}{|c|}{ Farelo de soja (Soybean meal) } & 20,44 & 20,44 & 20,44 & \multicolumn{2}{|c|}{20,45} & 20,44 \\
\hline \multicolumn{2}{|c|}{ Raspa de mandioca (Cassava scrapings) } & 0,00 & 5,64 & 11,28 & \multicolumn{2}{|c|}{16,92} & 22,56 \\
\hline Uréia (Urea) & & 0,27 & 0,39 & 0,52 & \multicolumn{2}{|c|}{0,64} & 0,77 \\
\hline \multicolumn{2}{|c|}{ Mistura mineral (Mineral mix) } & 1,13 & 1,13 & 1,13 & \multicolumn{2}{|c|}{1,13} & 1,13 \\
\hline \multicolumn{8}{|l|}{ Nutrient composition, $\%$} \\
\hline MS (DM) (\%) & 26,51 & 8,00 & 19,75 & 19,76 & 19,75 & 19,85 & 19,86 \\
\hline $\mathrm{MO}(O M)^{1}$ & 95,03 & 90,50 & 94,04 & 94,00 & 93,91 & 93,73 & 93,65 \\
\hline CIN (Ash) & 4,97 & 9,50 & 5,96 & 6,00 & 6,09 & 6,27 & 6,35 \\
\hline $\operatorname{PB}(C P)^{1}$ & 6,28 & 5,09 & 15,42 & 15,71 & 15,79 & 15,39 & 15,37 \\
\hline $\mathrm{EE}^{1}$ & 1,78 & 1,94 & 1,63 & 1,83 & 2,22 & 2,43 & 1,54 \\
\hline CHOT $(\text { TCHO })^{1}$ & 86,97 & 83,47 & 79,65 & 80,20 & 79,01 & 79,54 & 80,68 \\
\hline $\mathrm{CNF}(N F C)^{1}$ & 9,97 & 52,81 & 45,33 & 45,56 & 44,81 & 45,73 & 46,78 \\
\hline FDN $(N D F)^{1}$ & 77,00 & 30,66 & 34,32 & 34,64 & 34,20 & 33,81 & 33,90 \\
\hline FDA $(A D F)^{1}$ & 45,93 & 14,34 & 18,30 & 18,16 & 18,29 & 18,05 & 18,30 \\
\hline $\mathrm{NDT}_{1 \mathrm{x}}\left(T D N_{1 X}\right)(\%)^{*}$ & - & - & 69,50 & 69,82 & 70,65 & 71,17 & 70,42 \\
\hline $\mathrm{EL}_{\mathrm{Lp}}\left({ }^{*} N E_{L p}\right)(\mathrm{Mcal} / \mathrm{kg})$ & - & - & 1,56 & 1,56 & 1,58 & 1,56 & 1,57 \\
\hline
\end{tabular}


$\left(\mathrm{EL}_{\mathrm{Lp}}\right)$ das dietas experimentais (Tabela 1). As exigências de energias líquidas para mantença e produção dos animais, expressas em Mcal/dia, foram estimadas segundo o NRC (2001) para o cálculo do balanço de energia líquida.

As eficiências alimentares nos tratamentos foram determinadas pela relação entre a produção de leite corrigido para 3,5\% de gordura e a MS consumida.

Os resultados foram submetidos às análises de variância e regressão, utilizando-se o sistema de análise estatística e genética-SAEG(UFV, 1998).

\section{Resultados e Discussão}

A ingestão de MS (IMS) durante o experimento foi, em média, de $17,34 \mathrm{~kg}$, próxima ao valor predito $(16,89 \mathrm{~kg})$ pela equação preconizada pelo NRC (2001). O percentual médio de MS das dietas experimentais foi de 19,79\% (Tabela 2).

Não houve efeito da substituição do milho pela raspa de mandioca $(\mathrm{P}>0,05)$ sobre a IMS, expressa em quilogramas, em \%PV e em gramas por unidade de peso metabólico. Os valores encontrados para IMS estão coerentes com os modelos de predição observados na literatura para mantença e produção de animais com $450 \mathrm{~kg}$ de $\mathrm{PV}$ e média de produção diária de $25 \mathrm{~kg}$ de leite (NRC, 2001).

A semelhança nas IMS indica que os efeitos limitantes de ingestão, descritos por Campero (1994), Marques et al. (2000) e Jorge et al. (2002), referentes à pulverulência de produtos e subprodutos da raiz de mandioca não foram observados neste estudo, provavelmente porque a palma forrageira possui elevado teor de umidade, facilitando a mistura da raspa de mandioca nas dietas.
Não foram observados efeitos dos tratamentos sobre nenhum dos nutrientes avaliados, exceto o EE, que apresentou efeito quadrático com a elevação dos níveis de raspa de mandioca, como conseqüência dos teores deste nutriente das dietas. A equação de regressão comprova que o maior consumo de EE foi obtido com 51,25\% de inclusão da raspa de mandioca em substituição ao milho moído.

Ressalta-se que as dietas continham em média $45,64 \%$ de CNF na MS e que o NRC (2001) recomenda limite de 33 a $43 \%$ para evitar acidose ruminal e/ou outros problemas metabólicos associados à diminuição na IMS e à digestão da fibra dietética. Entretanto, esses efeitos deletérios não foram observados neste estudo (Tabelas 2 e 3 ).

A média de FDN, com base na MS, foi de $34,17 \%$ e está dentro dos limites recomendados pelo NRC (2001), de 25 a $44 \%$. O teor de FDN nas dietas resultou em consumo médio de $1,36 \%$ de FDN, em relação ao peso vivo, e não limitou o consumo de alimentos pelo enchimento do rúmenretículo. Possivelmente, foram mantidos padrões adequados de fermentação ruminal, por meio do estímulo à mastigação e salivação, com conseqüente tamponamento do rúmen, visto que os coeficientes de digestibilidade aparente da FDN foram semelhantes aos descritos na literatura.

Não houve diferença entre os coeficientes de digestibilidade $(\mathrm{P}>0,05)$ de $\mathrm{MS}, \mathrm{MO}, \mathrm{PB}, \mathrm{CHOT}, \mathrm{CNF}$ e FDN com a substituição do milho pela raspa de mandioca (Tabela 3). A digestibilidade do EE sofreu efeito quadrático com o aumento nos níveis de raspa de mandioca na dieta, de modo que, pela equação de regressão, verificou-se maior digestibilidade no nível de 55,86\% de substituição ao milho moído. Essas diferenças na digestibilidade do EE

Tabela 2 - Consumo médio de MS e de nutrientes, de acordo com as dietas experimentais Table 2 - Effects of increasing dietary levels of cassava scrapings on the average intake of nutrients

\begin{tabular}{|c|c|c|c|c|c|c|c|c|}
\hline \multirow[t]{2}{*}{$\begin{array}{l}\text { Consumo } \\
\text { Intake }\end{array}$} & \multicolumn{5}{|c|}{$\begin{array}{c}\text { Nível de substituição (\%) } \\
\text { Replacement level (\%) }\end{array}$} & \multirow[t]{2}{*}{ CV $(\%)$} & \multicolumn{2}{|c|}{$\mathrm{P}$} \\
\hline & 0 & 25 & 50 & 75 & 100 & & $\mathrm{~L}$ & Q \\
\hline $\mathrm{MS}(D M)(\mathrm{kg})$ & 17,95 & 17,22 & 16,95 & 17,92 & 16,95 & 4,55 & n.s. & n.s. \\
\hline MS (\%PV) (DM, BW\%) & 3,73 & 3,69 & 3,59 & 3,71 & 3,63 & 3,95 & n.s. & n.s. \\
\hline $\operatorname{MS}\left(\mathrm{g} / \mathrm{kg} \mathrm{PV}^{0,75}\right)\left(D M, g / B W \mathrm{~kg}^{0.75}\right)$ & 174,48 & 171,57 & 167,18 & 173,19 & 168,67 & 4,03 & n.s. & n.s. \\
\hline MO (OM) $(\mathrm{kg})$ & 16,88 & 15,94 & 15,78 & 16,50 & 15,87 & 8,44 & n.s. & n.s. \\
\hline $\mathrm{PB}(C P)(\mathrm{kg})$ & 2,80 & 2,58 & 2,72 & 2,79 & 2,59 & 9,29 & n.s. & n.s. \\
\hline $\mathrm{EE}(\mathrm{kg})$ & 0,29 & 0,32 & 0,39 & 0,44 & 0,27 & 12,39 & n.s. & $<0,001 *$ \\
\hline CHOT (TCHO) (kg) & 13,78 & 13,04 & 12,67 & 13,27 & 13,01 & 8,54 & n.s. & n.s. \\
\hline CNF (NFC) $(\mathrm{kg})$ & 8,14 & 7,84 & 7,71 & 8,03 & 6,33 & 9,12 & n.s. & n.s. \\
\hline $\mathrm{FDN}(N D F)(\mathrm{kg})$ & 6,42 & 6,53 & 6,47 & 6,31 & 7,98 & 7,61 & n.s. & n.s. \\
\hline FDN $(N D F, B W \%)(\% \mathrm{PV})$ & 1,33 & 1,40 & 1,38 & 1,33 & 1,36 & 7,87 & n.s. & n.s. \\
\hline FDA $(A D F)(\mathrm{kg})$ & 3,08 & 2,93 & 2,92 & 2,92 & 2,93 & 8,17 & n.s. & n.s. \\
\hline NDT $(T D N)(\mathrm{kg})$ & 12,48 & 12,02 & 11,98 & 12,75 & 11,94 & 12,53 & n.s. & n.s. \\
\hline
\end{tabular}

$\mathrm{r}^{2}$ - coeficiente de determinação (coefficient of determination); n.s. - não-significativo a $5 \%$ de probabilidade pelo teste $\mathrm{F}$ ( $n$.s.- not significant at $5 \%$ of probability by $F$ test); $P$ - probabilidade para efeito linear $(L)$ e quadrático $(Q)(P$ - probabilities for linear $(L)$ and quadract $(Q)$ effects $) ;{ }^{*} \hat{Y}=0,2940+0,0041 N S-0,00004 N S^{2}\left(R^{2}=0,64\right)$. 
parecem estar relacionadas à grande variação entre as amostras e ao método de análise adotado.

Os coeficientes de digestibilidade aparente dos demais nutrientes foram satisfatórios, demonstrando equilíbrio nos seus teores dietéticos, comprovado pela ausência de diminuição dos coeficientes de digestibilidade, mesmo com as maiores inclusões da raspa de mandioca em substituição ao milho moído. Dietas ricas em amido de maior velocidade de fermentação ruminal (amido da mandioca) poderiam interferir no crescimento dos microrganismos ruminais, favorecendo as bactérias amilolíticas e prejudicando as celulolíticas, diminuindo a digestibilidade dos nutrientes, principalmente a fibra dietética. Entretanto, esses efeitos não foram observados neste estudo. Os teores de NDT, estimados segundo Sniffen et al. (1992), não foram alterados $(\mathrm{P}>0,05)$ pelos tratamentos, observando-se média de $67,82 \%$.

Os valores referentes à concentração energética das dietas indicam a possibilidade de substituição do milho (fonte de energia tradicional na alimentação de ruminantes) pela raspa de mandioca (alternativa regional), que poderia substituir totalmente o milho sem ocasionar prejuízo na concentração energética das rações.

A produção média de leite (PL) durante todo o período experimental foi de $23,6 \mathrm{~kg}$ /dia e a produção corrigida para $3,5 \%$ de gordura (PLC), de 22,9 kg, com teor médio de gordura no leite de 3,33\%. Resposta linear decrescente $(\mathrm{P}<0,05)$ foi observada para PL, PLC, PG e EA com a substituição progressiva do milho pela raspa de mandioca (Tabela 4).

Estes resultados divergem dos achados de Campero (1994), que não notou efeito da substituição do milho pela farinha de banana ou farinha de mandioca nos concentrados de vacas Holandesas e mestiças Holandês:Crioula lactantes, criadas em pastagem de Brachiaria decumbens com suplementação de $1 \mathrm{~kg}$ de concentrado (18\% de PB e $3,0 \mathrm{Mcal} / \mathrm{kg}$ de ED) para produção de $2 \mathrm{~kg}$ de leite. Todavia, nesse estudo, os animais apresentaram média de produção diária de leite muito menor $(8,35 \mathrm{~kg}) \mathrm{e}$, conseqüentemente, exigências energéticas também menores, comprovando menor dependência em relação à energia do concentrado.

Ribeiro et al. (1976) avaliaram a substituição parcial do milho (50\% na matéria natural) do concentrado por raspa de mandioca ou melaço desidratado na dieta de vacas mestiças Holandês:Zebu com produção média diária de $12 \mathrm{~kg}$. Esses autores não encontraram diferenças significativas para produção de leite, corrigida ou não, e consumo de alimentos, mas registraram alterações no ganho de peso dos animais, observando-se maiores ganhos nos animais submetidos ao tratamento sem substituição do milho.

McCarthy et al. (1989) e Weiss et al. (1989) notaram redução na produção de leite quando substituíram o milho moído pela cevada, que apresenta característica semelhante à raspa de mandioca no que se refere à velocidade de degradação ruminal do amido. Esses autores relacionaram a queda na produção de leite à utilização menos eficiente da energia quando da utilização de amido de mais rápida degradação ruminal. Nocek \& Taminga (1991) e Reynolds et al. (2001), por sua vez, atribuíram ao amido do milho, por sua menor degradação ruminal (a maior parcela é degradada no intestino delgado), de forma que a glicose absorvida no intestino delgado seria mais bem aproveitada pelo ruminante para a produção de leite. Segundo Owens et al. (1986), quando o local de digestão do amido é alterado do rúmen para o intestino delgado, ocorre aumento na absorção de glicose, processo $42 \%$ mais eficiente energeticamente que a fermentação ruminal.

As diferenças nos processos de digestão, absorção e metabolismo entre o amido do milho e o da raspa de mandioca,

Tabela 3 - Digestibilidade aparente (DA) dos nutrientes, de acordo com as dietas experimentais Table 3 - Effects of increasing dietary levels of cassava scrapings on apparent digestibility (AD) of nutrients

\begin{tabular}{|c|c|c|c|c|c|c|c|c|}
\hline \multirow[t]{2}{*}{$\begin{array}{l}\mathrm{DA} \\
A D\end{array}$} & \multicolumn{5}{|c|}{$\begin{array}{c}\text { Nível de substituição (\%) } \\
\text { Replacement level (\%) }\end{array}$} & \multirow[t]{2}{*}{ CV (\%) } & \multicolumn{2}{|c|}{$\mathrm{P}$} \\
\hline & 0 & 25 & 50 & 75 & 100 & & $\mathrm{~L}$ & Q \\
\hline MO (OM) & 69,83 & 67,92 & 72,15 & 69,34 & 69,81 & 8,23 & n.s. & n.s. \\
\hline $\mathrm{PB}(C P)$ & 72,39 & 69,30 & 74,96 & 73,49 & 73,06 & 8,32 & n.s. & n.s. \\
\hline $\mathrm{EE}$ & 42,88 & 50,02 & 63,20 & 61,94 & 46,37 & 20,18 & 0,009 & $0,002 *$ \\
\hline FDN $(N D F)$ & 59,86 & 58,23 & 56,11 & 54,54 & 61,44 & 9,54 & n.s. & n.s. \\
\hline $\mathrm{NDT}^{1}(T D N)$ & 66,53 & 70,50 & 68,90 & 66,88 & 66,27 & 9,25 & n.s. & n.s. \\
\hline
\end{tabular}

$\mathrm{r}^{2}$ - coeficiente de determinação (coefficient of determination); n.s. - não-significativo a $5 \%$ de probabilidade pelo teste $\mathrm{F}$ ( n.s. - not significant at $5 \%$ of probability by $F$ test); ${ }^{1}$ Sniffen et al. (1992); P - probabilidade para efeito linear (L) e quadrático (Q) (P-probabilities for linear $(L)$ and quadract (Q) effects); ${ }^{*} \hat{Y}=40,5530+0,7597 N S-0,0068 N S^{2}$ $\left(R^{2}=0,86\right)$. 
Tabela 4 - Produção de leite (PL), produção de leite corrigida para gordura (PLC), teor de gordura do leite (\%G), produção de gordura (PG) e eficiência alimentar (EA), de acordo com as dietas experimentais

Table 4 - Effects of increasing dietary levels of cassava scrapings on milk yield (MY), fat corrected milk (FCM), milk fat percentage (Fat), milk fat yield (FatY), and feed efficiency (FE)

\begin{tabular}{|c|c|c|c|c|c|c|c|c|c|}
\hline \multirow[t]{2}{*}{$\begin{array}{l}\text { Parâmetro } \\
\text { Parameter }\end{array}$} & \multicolumn{5}{|c|}{$\begin{array}{l}\text { Nível de substituição (\%) } \\
\text { Replacement level (\%) }\end{array}$} & \multirow[t]{2}{*}{ CV (\%) } & \multirow[t]{2}{*}{$\begin{array}{l}\text { Regressão } \\
\text { Regression }\end{array}$} & \multirow[t]{2}{*}{$r^{2}$} & \multirow[t]{2}{*}{$P$} \\
\hline & 0 & 25 & 50 & 75 & 100 & & & & \\
\hline $\mathrm{PL}(M Y)(\mathrm{kg})$ & 24,99 & 24,30 & 22,90 & 23,69 & 22,14 & 5,13 & $\hat{\mathrm{Y}}=24,87-0,02 \mathrm{NS}$ & 0,79 & $<0,01$ \\
\hline $\mathrm{PLC}^{*}(F C M)(\mathrm{kg})$ & 24,59 & 23,56 & 22,31 & 23,00 & 21,16 & 7,96 & $\hat{\mathrm{Y}}=24,41-0,03 \mathrm{NS}$ & 0,82 & $<0,01$ \\
\hline$\% \mathrm{G} \quad($ Fat $\%)$ & 3,39 & 3,34 & 3,37 & 3,33 & 3,23 & 7,64 & $\hat{\mathrm{Y}}=3,38-0,0002 \mathrm{NS}$ & 0,66 & n.s. \\
\hline
\end{tabular}

$\mathrm{r}^{2}$ - coeficiente de determinação (coefficient of determination); n.s. - não-significativo a $5 \%$ de probabilidade pelo teste $\mathrm{F}$ ( $n$ s- not significant at $5 \%$ of probability by $F$ test) *corrigido a $3,5 \%$ de gordura; NS - nível de substituição (NS - level of replacement).

bem como os efeitos associativos entre estes alimentos e os demais ingredientes da dieta (palma forrageira, silagem de sorgo e uréia), parecem explicar as diferenças encontradas no desempenho dos animais.

Outra possível explicação seria a substituição de proteína verdadeira não degradada no rúmen pelo nitrogênio não-protéico (NNP), uma vez que o milho possui percentuais médios de $9 \%$ de PB ( $65 \%$ deste percentual encontra-se na forma de PNDR), enquanto a uréia, utilizada para corrigir as diferenças nos teores de PB do milho moído e da raspa de mandioca, poderia ser apenas fonte de NNP. Segundo o NRC (2001), essa substituição pode acarretar alteração da qualidade da proteína (perfil de aminoácidos) que chega ao intestino delgado (proteína metabolizável) para ser absorvida na forma de aminoácidos e peptídeos. Esse mesmo conselho informa que substituição dessa natureza pode limitar a quantidade de aminoácidos essenciais que chega ao intestino delgado, sobretudo metionina, o que provoca limitação da produção de leite.

A produção de gordura, em gramas por dia, decresceu linearmente $(\mathrm{P}<0,05)$ com a inclusão da raspa de mandioca, apresentando queda de $1,15 \mathrm{~g}$ para cada unidade percentual de substituição do milho nas dietas. Os teores de gordura não foram influenciados pelos tratamentos $(\mathrm{P}>0,05)$. A média $(3,33 \%)$ obtida é condizente com animais da raça Holandesa produzindo $25 \mathrm{~kg}$ de leite/dia. Portanto, menores produções de leite foram acompanhadas de menores produções de gordura. A igualdade nos teores de gordura no leite para todos os níveis de inclusão da raspa de mandioca em substituição ao milho comprova a não-interferência dos elevados níveis de CNF das dietas, visto que o decréscimo na concentração de gordura do leite era esperado com o aumento na suplementação de concentrados energéticos e com o fornecimento de fontes de carboidratos de rápida degradação ruminal. Zeoula (2001) afirma que outros fatores podem promover a diminuição da concentração de gordura no leite, pois quando maiores quantidades de amido chegam ao intestino delgado, ocorre aumento na disponibilidade de glicose, incidindo em elevação sérica de insulina e diminuição da atividade lipolítica no tecido adiposo.

O balanço de energia líquida (BEL) para os tratamentos atendeu às exigências de mantença e produção, segundo as equações do NRC (2001), apresentando, respectivamente, valores de 2,48;2,13;2,97;3,72 e 3,66 Mcal/dia para os níveis 0,25, 50, 75 e 100\% de substituição do milho moído. Aparentemente, não houve deficiência de energia para a secreção láctea. Os menores valores de BEL foram encontrados nos tratamentos com menor inclusão da raspa de mandioca, fato justificado pelas diferenças nas exigências para produção de leite em relação ao total de energia consumido. A utilização da sobra em energia provavelmente foi destinada ao crescimento e ao peso corporal dos animais, pois houve aumento diário de $555 \mathrm{~g}$ por animal.

A eficiência alimentar (expressa em kg de leite corrigido para 3,5\% de gordura em relação à IMS) foi reduzida com a elevação dos níveis de raspa de mandioca, apresentando redução linear de $0,001 \%$ para cada unidade percentual de substituição do milho moído. Todavia, os níveis de 0 e $25 \%$ de substituição do milho resultaram em valores semelhantes para eficiência alimentar (1,37).

Ressalta-se a viabilidade de substituição parcial, uma vez que a raspa de mandioca é mais barata que o milho, sendo considerada uma alternativa regional. A queda na eficiência alimentar para os outros níveis testados indica redução na conversão dos nutrientes dos alimentos em leite. Assim, para que seja vantajosa a substituição do milho pela raspa de mandioca, é necessária avaliação das diferenças nos custos desses ingredientes (milho e raspa de mandioca), incluindo os custos para a produção da raspa. A viabilidade de substituição do milho moído pela raspa de mandioca e o nível adequado de substituição dependem, portanto, da diferença de preço entre os ingredi- 
entes avaliados, da disponibilidade e do preço pago pelo leite, pois normalmente ocorre redução na produção dos animais.

\section{Conclusões}

A raspa de mandioca não substitui o milho em dietas para vacas leiteiras, pois interfere negativamente no desempenho produtivo e na eficiência alimentar. A substituição do milho pela raspa de mandioca não afeta, no entanto, o consumo, a digestibilidade dos nutrientes e o teor de gordura do leite.

\section{Literatura Citada}

ASSOCIATION OF OFFICIAL ANALYTICAL CHEMISTS - AOAC. Official methods of analisys. 13.ed. Washington, D.C.: 1980. $1018 \mathrm{p}$.

BEHMER, M.L.A. Laticínios, leite, manteiga, queijo, caseína e instalações. 3.ed. São Paulo: Melhoramentos, 1965. 294p.

CAMPERO, J.R. Harina de banano o yuca como substituto del maiz en raciones para vacas lecheras manejadas bajo pastoreo en el tropico. Archivos Latinoamericanos de Producion Animal, v.2, n.2, p.177-186, 1994.

COCHRAN, R.C.; ADAMS, D.C.; WALLACE, J.D. et al. Predicting digestibility of different diets with internal markers: evaluation of four potential markers. Journal of Animal Science, v.63, n.5, p.1476-1483, 1986.

HALL, M.B. New equations may improve NSC estimating. Feedstuffs, n.69, n.37, p.12-14, 1997.

JORGE, J.R.V.; ZEOULA, L.M.; PRADO, I.N. et al. Substituição do milho pela farinha de varredura (Manihot esculenta, Crantz) na ração de bezerros holandeses. 2. Digestibilidade e valor energético. Revista Brasileira de Zootecnia, v.31, n.1, p.205-212, 2002.

MARQUES, J.A.; PRADO, I.N.; ZEOULA, L.M. et al. Avaliação da mandioca e seus resíduos industriais em substituição ao milho no desempenho de novilhas confinadas. Revista Brasileira de Zootecnia, v.29, n.5, p.1528-1536, 2000.

MATTOS, W.R.S. Limites da eficiência alimentar em bovinos leiteiros. In: REUNIÃO ANUAL DA SOCIEDADE BRASILEIRA DE ZOOTECNIA, 41., 2004, Campo Grande. Anais... Campo Grande: Sociedade Brasileira de Zootecnia, 2004. p.239-247.

McCARTHY, R.D.; KLUSMEYER, J.L.; VICINI, J. H. et al. Effects of source of protein and carbohydrate on ruminal fermentation and passage of nutrients to the small intestine of lactating cows. Journal of Dairy Science, v.72, n.8, p.2002-2016, 1989.

MELLO, R.P.; SILVA, J.F.C.; CAMPOS, O.F. et al. Milho desintegrado com palha e sabugo, raspa de mandioca e sementes de sorgo moídas, em concentrados para vacas em lactação. Revista da Sociedade Brasileira de Zootecnia, v.5, n.2, p.105-118, 1976.
NATIONAL RESEARCH COUNCIL - NRC. Nutrient requirements of the dairy cattle. 7.ed. Washington: D.C.: National Academy of Science, 2001. 363p.

NOCEK, J.E.; TAMINGA, S. Site of digestion of starch in the gastrointestinal tract of dairy cows and its effect on milk yield and composition. Journal of Dairy Science, v.74, n.10, p.3598-3629, 1991.

OWENS, F.N.; ZINN, R.A.; KIM, Y.K. Limits to starch digestion in the ruminant small intestine. Journal of Dairy Science, v.63, n.7, p.1634-1642, 1986.

PEREIRA, J.P. Utilização da raspa e resíduos industriais da mandioca na alimentação animal. Informe Agropecuário, v.13, n.145, p.28-41, 1987.

REYNOLDS, C.K.; CAMMELL, S.B.; HUMPHRIES, D.J. et al. Effects of postrumen starch infusion on milk production and energy metabolism in dairy cows. Journal of Dairy Science, v.84, n.10, p.2250-2259, 2001.

RIBEIRO, P.J.; MOREIRA, H.A.; VILELA, H. et al. Melaço desidratado e raspa de mandioca como substitutos parciais do milho para produção de leite. Arquivos da Escola Veterinária UFMG, v.28, n.2, p.193-200, 1976.

SILVA, J.F.C.; LEÃO, M.I. Fundamentos de nutrição dos ruminantes. Piracicaba: Livroceres, 1979. 380p.

SILVA, D.J. Análise de alimentos (métodos químicos e biológicos) Viçosa, MG: Universidade Federal de Viçosa, 1990. 165p.

SKLAN, D.; ASHKENAZI, R.; BRAUN, A. et al. Fatty acids, calcium soaps of fatty acids, and cottonseeds fed to high yielding cows. Journal of Dairy Science, v.75, n.9, p.2463-2472, 1992.

SNIFFEN, C.J.; O'CONNOR, J.D; Van SOEST, P.J. et al. A net carbohydrate and protein system for evaluating cattle diets. II carbohydrate and protein availability. Journal of Animal Science, v.70, p.3562-3577, 1992.

UNIVERSIDADE FEDERAL DE VIÇOSA - UFV. SAEG - Sistema de análises estatísticas e genéticas. Versão 7.1.Viçosa, MG: 1997. 150p. (Manual do usuário).

Van SOEST, P.J.; ROBERTSON, J.B.; LEWIS, B.A. Methods for dietary fiber, neutral detergent fiber, and nonstarch polysaccarides in relation to animal nutrition. Journal of Dairy Science, v.74, n.10, p.3583-3597, 1991.

WEISS, W.P.; ERICKSON, D.O.; ERICKSON, G.M. et al. Barley distillers grains as a protein supplement for dairy cows. Journal of Dairy Science, v.72, n.5, p.980-987, 1989.

ZEOULA, L.M.; CALDAS NETO, S.F. Recentes avanços em amido na nutrição de vacas leiteiras. In: SIMPÓSIO INTERNACIONAL EM BOVINOCULTURA DE LEITE: NOVOS CONCEITOS EM NUTRIÇÃO, 2., 2001, Lavras. Anais... Lavras: Universidade Federal de Lavras, 2001. p.199-228. 